\title{
The Impact of School Transformation on School Officials
}

\author{
Natasha Welcome \\ Metamorphosis Education Consultants, USA
}

\begin{abstract}
The research study investigates the impact of school transformation on school officials. It sets out to fill a gap in the knowledge base as it relates to school transformation as the effects on school officials is specifically addressed. Three questions were answered by a simple literature review method. Several papers that dealt with school transformation were analyzed. The types of transformations were placed in three categories, institutional, curriculum and personal transformations. By use of the qualitative method various relevant themes were found. There were three distinct findings in this paper. The first being, there is not a common indicator that schools, or institutions of learning is ready for transformation. Since each transformation is different, so are the indicators. Secondly, school officials should be included as much as possible in the transformation plans. In this way they would be better positioned to change in order to demonstrate flexibility and cooperation. Thirdly, the process and product of school transformation do have a resemblance which is measured the predictability of the outcome.
\end{abstract}

\section{Introduction}

The researcher witnessed a total school transformation that changed my life forever. It was early in my teaching career. It uprooted my then education philosophy in areas of school management, pedagogy, teacher job security, and school culture/ branding. This tectonic shift in the educational landscape dislocated and relocated the trends of education as it was back then. Wondering, 'if it was even legal or mentally healthy for anyone involved?' The researcher was teaching in at a small private school that possessed a great vision and mission. However, like every institution, there is a set time for transformation. When that time has come, there are only two options transformation or death. The institution has come to the end of itself and fortifying the old model cannot be recommended. This is synonymous with a small caterpillar that cannot fly or pollinate flowers. Feeding the caterpillar to become bigger still cannot afford it the ability to fly or pollinate flowers. Adding more legs to it is not the answer either. The next stage of its life requires attributes that are not found in its present stage. Therefore, it must totally change its state of existence and become a butterfly. Some consultants were sourced to facilitate the transformation. They began a series of interviews and observations. Interviews were done with former, former parents, present parents, present students, and lastly the staff. Their classroom observations became quite intrusive. The researcher had a consultant in here classroom at least four times a week for several hours and this lasted for 3 months. They uprooted all the pillars of the school. Which were school management, pedagogy, human resource, and school culture. Several actions were taken which were the firing of the school's director and later the principal and the dissolving of the school board. In the area of pedagogy, some professional developments of new classroom trends were introduced such as technology, differentiation, etc. The road towards international education was introduced which instituted curriculum change. Some private coaching occurred, the researcher was taken to another school just to observe their classroom culture and teaching strategies. Approximately two-thirds of the staff were relieved of their duties on a day that felt like judgment day. The name and uniform of the school were changed and with it went an old school culture that created a vacuum for a new one. It felt like we were living in a house that is under major construction. There were chills at every meeting. It often felt overbearing and in many ways triggered feelings of anxiety for the staff. Even the few of us who were seen as competent had to lean on each other to maintain our competency. The question of whether there was anything wrong with transformation, surfaced. Transformation is inevitable for the success of any form, school transformation is no exception. However, the question that must be foremost in our mind is, does it have to be as radical as explained above? Can it by some chance be more palatable and friendly? Those were the thoughts that haunted me for years. Therefore, this paper is a step in the direction of answering some questions. The researcher was triggered by the product, not necessarily the process. These details were shared at the Ireland International Conference on Education where this paper was birthed.

\section{Research Background}

Several studies focus on changes in school environments and school programs and curriculums. Those studies have mostly leaned towards the positive product of the transformation. However, there is a 
lack of information relating mostly to the process which will highlight the raw emotions that happens to be the vehicle on which the transformation occurs. Because of this lack, schools desiring a transformation have been lacking the much valuable information directly relating to the process. This lack can result in schools not knowing the normal impacts of transformation whether deemed good or bad. Schools in the process of transformation can resort to returning to their former state when emotions that seem abnormal begin to manifest. They may equate positive processes with positive outcomes and negative processes with negative outcomes. However, the process of transformation may be much more intricate than obvious.

\section{Purpose of study}

Considering all the complexities mentioned above, the relationship between the process and the product is unclear, they may be related in ways that are not easy to understand. Therefore, this paper seeks to shed some light on the impact of school transformation. The structure of this paper recognizes that if some work that was previously done is carefully combed, they may reveal hidden impacts that the work did not directly address. Therefore, this paper serves as a magnifying glass to highlight important details that may have been glossed over unconsciously or consciously by others. It is aimed at giving a unique view of school transformation which can be used as a roadmap for future transformations. This study is intent on using evidence from other words and telling the untold story behind the transformations covered. In so doing these questions will be answered:

- Is there a common indicator that a school/ institution is ready for transformation?

- In what ways do employees must change to accommodate a school transformation?

- Is there a resemblance between the process and the product of school transformation? If so how related are they?

The purpose of this study is to add a unique twist to information already gathered on school transformation. It will serve as an informant to schools that are preparing for a transformation. It will also serve as a guide to personnel who are helping to reform schools. In so doing, it will lessen anxieties relating to transformation and increase confidence as many travel the road to transformation.

\section{Review of the Literature}

'I Felt More Traumatized than Trained': Active Shooter Drills Take Toll on Teachers
Blad and Will [1] In the narrative article from Education Week explained that ALICE Institute is noted for using uses real-life scenarios to train teachers and school staff how to react to active shooting situations. School employees are asked to kneel with their faces to the wall and be shot with guns that shoot plastic pellets. Teachers were shooting teachers and the screams were horrendous. Elisabeth Yanelli remarked that she felt more traumatized than trained. She further commented that there is no need to create a training so extreme since other drills are not as traumatic. According to safety consultant Michael Dorn, the model used for the active-shooter training has resulted in injury and filed lawsuits by some staff members. A coauthor of NASP and the National Association of School Resource Officers called Reeves responded with alternatives such as the use of rubber bullets instead of plastic and the access to mental health support after drills.

\section{Finding Purpose by Teaching ESL}

Marre [2] explained in her article that her school went through some changes which led to the loss of her job as a teacher. She elaborated about the emotional roller coaster that the staff encountered from the months of interviews, meetings, rumors, etc that preceded the end of her tenure. Marre was trained on the inside and received extrinsic motivation from loved ones to maneuver through the transition. She adheres to the external stimuli and was able to continue her schooling which took her down a slightly different path and opened her up to a new world of possibilities.

Transitioning the Team: Supporting Distance Supervised Doctor of Business Administration Students Through Collaborative Online Workshop

Carr [3] is concerned not with institutional transformation but with students' transition. The University of Chicago Business School designed a program specifically for middle and senior managers who had at least 10 years of experience and a master's degree. It was designed to solve the issue of tight time constraints. Therefore, the program was a hybrid, having both online lectures and on-campus workshops. The program was introduced in California and Shanghai, China. One full year of coursework and a thesis was required for completion. A new initiative of pairing thesis students was introduced. The literature that was reviewed came under headings of 'Sense of belonging', 'Educational transitions', and 'The practice under scrutiny.' Carr [3] found that research supports the notion that challenges such as frustrations and anxiety while studying are lessened when students are put into peer groups. This activity generates a sense of belonging and has been found to be more critically needed for online classes. Second, 
Carr [3] found that there was a considerable amount of work done on the transition from elementary to secondary school and from secondary to territory education. However, there had not been much work done in relation to postgraduate students who transitioned from graduate studies. There seemed to be an assumption that students' prior background does not warrant support for their forward thrust. Third, the idea that peer support would be granted to doctoral students was scrutinized by lab work. This type of scrutiny is quite new to education and is practiced more in the field of social sciences. This study concludes that the transition to a postgraduate degree was much easier when students received support from their peers and the supervision of that support is efficient. On the contrary, students who were grouped together as completing studies with similar topics did not benefit from much support once they did not move with synchronicity.

\section{Adult Learners' Experiences in Accelerated Degree- Completion Programs at Christian Colleges: Transactions and Transformations}

Decker [4] uses the qualitative data collection method to study the experiences in accelerated degree completion programs at Christian colleges. There were 30 participants from 4 Christian colleges. The aim of this study was to investigate the experiences of these adult learners who were all in full-time jobs and in some cases having to care for their children or elderly family member. As a result, adult students reported considerable levels of emotional support and showed gratitude to the way biblical teaching and devotional practices helped them develop holistically. This finding was also true for participants who did not choose the school specifically for its faith-based culture.

\section{New Schools in New Orleans: School Reform Both Exhilarated and Imperiled by Success}

The literature exemplifies a huge undertaking of the school system in New Orleans to embrace reformation. The situation described by Horne [5] is a multilayered one. He began with explicit data about the layout of the educational landscape in New Orleans as it relates to schools' academic competence, schools' governmental structure, and students' performance. Each of the above topics was indicating the need for urgent reformation. This was the condition of schools in New Orleans before the Katrina storm. More specific data on a case-by-case basis was added to create a picture of the deplorable education condition. However, the storm added momentum to what a staled dated issue. Officials gave the school districts a 5 years ultimatum to create transformation. There were several factors that fastpaced the transformation. First, the study mentioned that since teachers were scattered, it nullified the collective bargaining agreement by the Teachers Union, thus creating a more conducive atmosphere to create change. Second, there was a competition for students who remained in New Orleans after Hurricane Katrina. It changed the old notion of schools providing jobs for adults rather than being learning environments for students. Contribution to this rise was made by Teach for America, Teach NOLA, and New Teacher Project. Since there was a deficit of human resources, organizations such as NSMO were able to train new school leaders with cutting-edge mindsets. Suspicious parents of private school students, who would have previously linked school reformation to a ploy to lead their kids back into the low-income school system, relinquished those concepts. This surge of educational competency, however, did not happen without negative drawbacks. There were cases where special needs students were turned away in efforts to keep the test scores soaring. Students also with behavioral were expelled if the effort to focus on students who showed a promise of yielding better fruits.

The outcome of the New Orleans school reformation is many. Paul Vallas, the superintendent of RSD extended the school day as well as year. The data showed that charter schools enrollment rose by $15 \%$ from 2007 to 2010. There was direct confrontation on racial inequality to add equity to the school system. There was a high level of government financial support channeled to help the drive. At the time of the research, there were efforts to extend the paradigm. The schools were said to be 'good enough' not necessarily 'excellent.'

\section{Data Science and Human Behaviour Interpretation and Transformation}

The research study was set out to answer two questions which are: Do I have anything important and if so what do I have? Human behavior has several variables, it is considered multi-modal in nature. These variables are emotions, cognitions, attributes, and behaviors. The question of, do I have anything important, is concerned with the researcher's observation of some aspect of human behavior adequately addresses the observation. The next question, if so, do I have concerned about the best explanation of the relationship between variables. The research problem poses the notion that human behavior is multimodal with content coming from facial expressions, gestures captured from images, video audio, text, etc. A comparison matrix was developed to measure the intensity of behavior that was measured. System conditioning is used to set devices used in the classroom for both teachers and students. Singh (2021) [6] found that human behavior is situational and dimensional therefore it fluctuates 
according to circumstances. There are behavior changes that come through various interventions.

\section{Digital Literacy Competencies Among English Teachers of Nepal}

Are They Ready For Online Instruction? The transformation described in this study by Saud [7] is one that was caused by the global shutdown. Classes in Nepal's government educational institutions radically changed from face to face to online. The discipline that is the focus of this study is English as a Foreign Language (EFL). The teachers and students associated with this discipline were not familiar with online modes of learning, hence the need for transformation. Not only were the stakeholders not familiar with digital learning, but the curriculum system was also only supported in the brick-andmortar model. An online language system named computer-assisted language learning (CALL) is used only in private, urban schools but not government institutions. There was a need for teachers and students to be digitally literate and master online applications to skillfully transition into governmentrecommended online learning. Therefore, the research was concerned with examining the digital competencies of the EFL teachers in Nepal. This was matched to their pedagogical content knowledge to see if they can adequately express relevant pedagogy in their instruction. The study employed a quantitative method for data collection. A questionnaire was adopted by Son et al., [8] and Cote and Miller [9]. This large study involved 426 Nepalese teachers at the primary and secondary school levels. They ranged from below 35 to above 50 years old. Many of the educators had a master's degree with a few had a $\mathrm{Ph} . \mathrm{D}$. Other variables were sex, province, teaching experience, working area, employment status, and employment sector.

The findings were that there was an overall agreement to have competency level when teachers were asked if they thought that they were ready to perform digital tasks. However, as the topics of resizing photos, recording, and editing sound more teachers gave a 'no' answer. The majority of teachers said that they learned computer skills from formal training, others were self-taught, though most learned from various sources. The majority of teachers reported that the Nepalese school system did not make provision for online learning. However, most EFL teachers said that online teaching was not a burden for them. As it relates to the continuous use of online learning, 76\% responded that it was a method for the pandemic and similar events. On the flip side, $30 \%$ said it should replace face-to-face learning. At the end of the crisis, Nepalese EFL teachers were equipped to teach online, $53 \%$ were from rural areas. The limitations were that the snowballing method used was not efficient to capture the targeted population.
The questionnaire format required digital literacy and the internet, therefore, $56 \%$ of the participants were 25 years and under.

Findings on Charter Schools Reported by Investigators at the University of Wisconsin ("the Price of Disaster" the Charter School Authorization Process in Post- Katrina New Orleans)

The paper from Vertical News [10], provided only the findings of Charter Schools as a means to reform the educational system of New Orleans after Hurricane Katrina. This was found to be so because they are connected to privatization. This has been a controversial alternation to the reformation described above. The vision should be to marry accountability and autonomy to improve academic achievement. However, there are two integral aspects that assist in its operation, which are governance and vision. The charter authorization process was studied which usually proposes a colorblind approach. However, the process has racial formation and racialized power solidification embedded. it was found that the process acts as a traffic regulator to the educational market.

\section{How New Orleans Made Charter Schools Work}

Since Katrina, the Crescent City School produce what some experts believed to be the most rapid academic improvement in American history and created a reform model other cities are trying. This paper by Osbourne [11] emphasized that though charter schools in the United States are at a disadvantaged financial position still they produce a higher graduation rate than public schools. However, it provided the balanced view that some charter schools have disappointing results. Among the negative results are, before Hurricane Katrina, $62 \%$ of the students in Louisiana attended failing schools. Less than one in five students went to college in New Orleans. There were incidents of $100 \%$ failure at the Graduate Exit Exam (GEE) on the first attempt, at that time the exam was set at a seventh-grade level. Then a radically new governmental system created a transformation from public schools to charters. Katrina created the avenue as it eliminated the normal political bureaucracies. Leslie Jacobs, a former state superintendent who was asked to judge some A students' essays made the discovery public. Jacobs who had been a Cornell University graduate found that their essays had errors like subject and verb agreement, sentence structure, paragraphing, and punctuation. She found them unfit for an entry position at her insurance firm and decided to call for action. Then Jacobs convinced the then Secretary of Education to use money that was there to establish new Charter Schools. Sarah Usdin, the director of Teach for America founded NSNO, an organization designed to assist charters where needed. National 
Association of Charter began to vet RSD for a commitment to quality. Paul Pastorek who was the acting State Superintendent became the head of RSD and immediately began to build new school buildings.

Despite great transformation efforts, the reopening of schools in September 2006, was met with insufficient textbooks and relevant furniture and very large class sizes. There was a push to get buildings ready for 10000 students returning with their families. There were several hiccups and procedures that did not always go according to protocol, for example, they had no cash flow, line of credit, or working capital but they began to build. During the building process, there were also cases of incompetencies among builders resulting in deadlines not being met and a surge of negative emotions. This did not come without a struggle, many wanted the schools to return to OPSB and were angry with the new system.

The results of this transformation were as follows. Teach for America played a major role in providing teachers for New Orleans poverty areas, most of whom were young and white. Great teachers were hired and others were fired, most of whom were black. The teachers who were rehired were forced to be flexible since there was no sense of job security like OPSB provided. A new leader was created to deal with operations allowing principals to be bound to academics. A sense of urgency and was created. Every year lends itself to a new alternative, advancing the reformation to a greater level. Parents were not bound to send their children to the school in their district. They could have chosen whichever school they desired. New Orleans was able to create school cultures that were more conducive to learning. With the new system, it became much easier to close failing schools. There was a demarcation between overseeing schools and running schools. The RSD focused on overseeing schools and did not get caught up with the operations of the schools.

Transformation from traditional schools to alternative schools: curriculum leadership of the principals of Taiwanese aborigines This qualitative study was done by Hsieh et al. [12], focused on school transformation as it relates to curriculum

The changes in nationwide curriculum also included the aborigines who were previously marginalized. This paper focused on the views of employees at two Taiwanese aborigines that have undergone a successful transformation. These are the principals, directors, team leaders, and teachers (eight persons in total) in two schools on the school principal-led curriculum transformation. The results state that the principals were successful in changing the beliefs of the teachers' philosophy as it relates to the curriculum. They were able to establish a curriculum paradigm that was new and different from the mainstream classroom. This approach was recommended to other schools that desire to transform their curriculum.

Transformation in Primary School Sciences Education in the Transition Process from the Empire to the Republic: Science Education in 1924 Primary School Curriculum

Aslan, E., and Serin [13] purposed their research to find out how the "elementary science education" has changed in the first curriculum with the transition from the Ottoman Empire to the Republic of Turkey. "Primary schools" were affected by the transition to the Republic regime, after the establishment of the Republic of Turkey. The study compared the programs of the "Empire" and "Republic". After careful examination and consideration, it was evident that primary school science was transformed. There were assessments and publicans to prove hypothesis. 'In the first program which was approved by the Republic of Turkey is given by transliteration to the Latin alphabet. The study has a feature that has important contribution for the future researchers on "science education" in both the Eras of Empire and Republic.

\section{Analysis of Findings}

Is there a common indicator that a school/institution is ready for transformation?

The research proves that there is no one common indicator that schools/ institution are ready for transformation. Contrary to that belief, there are indicators of transformation, but they vary from study to study. First, for charity's sake, the transformations studied in this paper could be placed into three categories- institutional, curriculum and personal. Institutional transformation referred to the cases where the entire educational institution was transformed as referenced in the introduction. Vertical News [8] stated that "Charter schools because of their entanglement with privatization remain one of the most publicly contested and controversial educational reform initiatives." This statement suggests that there was a need for reformation however, the path was unclear because of bureaucracy such as racial bias. However, they did not give specific tell-tale signs because the transformation was needed. Another much older institutional transformation study done by Horne [5] specified academic failure and vision diversion among others were clear indicators that a total institutional transformation was needed. However, unlike the charter school authorization process mentioned by Verticle News, Horne noted that transformation was without controversy because the Teachers Union system went sterile during the hurricane. A more recent institutional transformation reported by Osborne [11] was considered "the most 
radical overhaul of any type in any school district in at least a century." There was mention that student achieve needed to be raised and the old governmental system was criticized for the school's failing state. It can therefore be summarized that there is a common thread of malfunction that creates the cry for institutional transformation. The second type of transformation noted is the curriculum/ program transformation. This study showed that there were two types program/ curriculum transformation, which are planned and situational or unplanned. Carr [3] had a planned curriculum transformation to support students who would have otherwise been working independently in a distance educational doctoral thesis program. It was noted that program transformation was needed because of the demographics of most students which included strong family commitments, busy social life and striving career commitments. The new doctoral thesis method was predicated on finding a unique strategy that will allow students to maintain the above-mentioned commitments and still work on their thesis. Aslan et al. [14] was triggered to transform their elementary Science curriculum after a change in the country's status from an empire to a republic. The only situational curriculum change that was mentioned in this work was that of Blad and Will [1]. The precursor for this transformation was the urgent need to keep school officials safe should a school shooting occur. Therefore, several variables can contribute to a curriculum or situational transformation. The third type of transformation found in this work is one that is a personal unplanned transformation that is a spin off from a larger transformation. Marre [2] unexpectedly birthed a new profession after the loss of her job.

\section{In what ways should school officials need to change to accommodate a school transformation?}

The works cited did not specifically highlight the right type of behavior that School officials need to drive a school transformation. However, after carefully combing through the data, there are several variables that appeared through deductive reasoning. Total school transformation is the most dramatic because there are several changes and usually require changes to the core of the institutional structure. These can vary from but not limited to change of managerial structure and team, vision, mission, philosophy and curriculum which flows into daily operation. Because of the nature of such transformation, school officials are expected to adopt to an entirely different structure. Some school officials are even let go or replaced. Osbourne [11] recorded the role Teach for America played in replacing positions held by former New Orleans educators. This brings us to the matter of the flexibility needed to be portrayed by schools' stakeholders such as educational leaders, teachers, students and parents to name a few. An integral part of transformation is the flexibility that should be exercised by school officials. While again, there is no formal request made to school officials to prepare them for any of the transformations studied in these works, yet flexibility is a key ingredient. In many cases schoolteachers had to develop new skills to work under a different educational structure as in the case of Horne [5]. In several other cases flexibility to shift from one curriculum / program to the next is an underlying prerequisite. This is seen in work done by Saud [7], there was a rapid transformation from face to face to online instruction at the beginning of the global pandemic. Marre [2] also exercised that flexibility when during a transformation she was fired from her position, this skill gave her a chance to experience a personal transformation. This type of transformation can be inferred for every school transition where changes are made in human resource. However, it is quite common to simply allow the affected staff to quietly disappear from the radar. Nevertheless, this paper acknowledges this type of flexibility. Marre [2], explains her personal account of transformation and created proof that during a major transformation, there are several spins off transformation that goes unnoticed. That is also a noteworthy point for school officials to take into consideration. The favorable mention of the absence of a union in one school transformation encouraged the belief that opposition is a deterrent factor to change. This quality revealed that school officials should first understand the need for a transformation. The other question that arises is, 'can a total transformation happen in the presence of a teachers' union.' If so, what are the steps that should be taken to bring a teachers' union onboard so that a school transformation is still possible? Another change that school officials need to make to accommodate school transformation would be that the process can be explained previously. This is allow for a mental preparation and therefore lessen anxieties. Blad et al. [1] described how the school shooting training caused a feeling of trauma rather than training. The school security consultants did not only noted the need for the preparation of school officials but also follow up mental health support for such transformative training.

Is there a resemblance between the process and the product of school transformation? If so, how related are they?

Poveda et al. [15] did a study on the emergent cross cutting themes as it relates to educational intervention. The study attempts to shed some light on the process and product of educational transformation. One of the streams that requires close attention was the reconstruction of intervention outcomes. They stated that an educational 
intervention should have clearly defined objectives from the start, a well-defined assessment plan (ideally with pre-post measures and comparison. They should also have a carefully planned timeframe and sequential organization. There should also be an evidence-based approach to an educational intervention with clearly defined objectives from the start, a well-defined assessment plan (ideally with prepost measures and comparison groups), and given the constraints under which both formal and nonformal educational organizations operate. A carefully planned timeframe for school/educational transformation should be given and there should be sequential organization. However, defining resemblance is key to answering our final research question. Also, since there are irregularities in measuring the process against the product, there needs to be a clear explanation on this. Is is easier and more logical to measure a process with another process or a product with a product. However, the measuring of process and product here basically alludes to predictability of the outcome of the transformation in question. Therefore, the resemblance between the process and the product can only be measured if there is a structured approach as mentioned above. Also, the approach as to be known and not secretive so that it would be evident. According to the school transformations studied in this paper, there is a resemblance between the process and product. $100 \%$ of the school transformations were planned, some more carefully strategised than others. For example, they ranged from strategic planning for entire state approach to education to emergency plans put into action at the beginning of the pandemic. $86 \%$ of the school transformations showed a process- product resemblance. The reason for this could be because there have been several changes in the process to amount to the desired product. This is proof that transformations are basically product driven. There is one case where the product was unexpected and totally the opposite of what was supposed to be the outcome. There have also been cases of an evolving ideal product, in this case, the transformation started the process to the desired outcome.

\section{Conclusion}

On a serious note, there is a common thread that runs through the studies cited above. Schools' systems will at some point require transformation, however, the process that is used to bring about the product and lessons learned should be honed. There are several lessons that can be encapsulated. Many educational transformations are controversial at the beginning. The Each transformation received either desired or undesired results when matched to their hypothesis. All of the Schools found unexpected aspects of transformation that were not discussed in their primary purpose.

\section{References}

[1] Blad, E., and Will, M. (2020, Jan). 'I felt more traumatized than trained': Active-shooter drills take toll onteachers. The Education Digest, 85, 4-10. https://middle sexcc.idm.oclc.org/login?qurl=https $\% 3 \mathrm{~A} \% 2 \mathrm{~F} \% 2 \mathrm{Fwww} . \mathrm{pr}$ oq uest.com $\% 2$ Fmagazines $\% 2$ Fi-felt-more-traumatized-tha n-trainedactive $\% 2$ Fdocview $\% 2 F 2325695890 \% 2 \mathrm{Fse}-2 \% 3 \mathrm{~F}$ accountid\%3D 40481. (Access Date: 11 September 2022).

[2] Marre, A. (2021 January) Finding purpose by teaching ESL. Teach Magazine: Education for Today and Tomorrow. https://teachmag.com/archives/1206. (Access Date: 11 November 2022).

[3] University of Otago. (n.d.). Transitioning the Team: Supporting Distance Supervised Doctor of Business Administration Students Through Collaborative Online Workshop. Journal of Open Flexible and Distance Learning, 25 (1).

[4] Decker, A. (2017). Adult learners' experiences in accelerated degree-completion programs at christian colleges: Transactions and transformations Available from ERIC. (1968424965; ED576010). https://middlesexcc.idm .ocl c.org/login?qurl=https $\% 3 \mathrm{~A} \% 2 \% 2 \mathrm{Fwww}$.proquest.com $\% 2$ Fdissertations-theses $\% 2$ Fadult-learners-experiences-acc elerated-degree $\% 2 \mathrm{Fdocview} \% 2 \mathrm{~F} 1968424965 \% 2 \mathrm{Fse}-2 \% 3 \mathrm{~F}$ accountid\%3D4048. (Access Date: 17 September 2022).

[5] Horne, J. (2011). New Schools in New Orleans: School Reform Both Exhilarated and Imperiled by Success. Education Next, 11 (2), 14-24.

[6] Singh, A. (2021). Data Science and Human Behaviour Interpretation and Transformation. Journal of Learning and Teaching in Digital Age, 6(1), 1-7.Principals of Taiwanese Aborigines. Asia Pacific Education Review, 22 (1), 53-66.

[7] Saud, M. S. (2021). Digital literacy competencies among English teachers of Nepal: Are they ready for online instruction? Malaysian Online Journal of Educational Technology, 9 (4), 1-13. NewsRx. Findingson Charter Schools Reported by Investigators at University of Wisconsin ("the Price of Disaster" the Charter School Authorization Process in Post Katrina New Orleans). Education Letter. April 7, 2021: p 205. DOI: 10.52380/mojet.2021.9.4.204.

[8] Baltà-Salvador, R., Olmedo-Torre, N., Peña, M., and Renta-Davids, A. I. (2021). Academic and emotional effects of online learning during the COVID-19 pandemic on engineering students. Education and information technologies, 1-28. Advance online publication. DOI: 10.1007/s10639-021-10593-1.

[9] Robin Miller, Catherine Weir, Steve Gulati Journal of Integrated Care. ISSN: 1476-9018 Open Access.

[10] Vertical News. (2021). 4.8 Findings on Charter Schools Reported by Investigators at the University of Wisconsin ("the Price of Disaster" the Charter School Authorization Process in Post- Katrina New Orleans). 
[11] Osborne, D. (2015, June- August). How New Orleans made charter schools work: since Katrina, the Crescent City's schools have produced what some experts believe to be the most rapid academic improvement in American history--and created a reform model other cities are trying." Washington Monthly, vol. 47, no. 6-8, June-Aug. 2015, pp. 65+. Gale Academic OneFile, link.gale.com/apps/doc/A41 9926353/AONE? $\mathrm{u}=$ anon $~ 84 \mathrm{c} 5 \mathrm{e} 529 \&$ sid=googleScholar\& xid=1b01994a. (Access Date: 18 November 2022).

[12] Hsieh, C. C., Tseng, H. K., and Chen, R. J. C. (2021). Transformation from traditional schools to alternative schools: curriculum leadership of the principals of Taiwanese aborigines. Asia Pacific Education Review (2021) 22 (1) 53-66. DOI: 10.1007/s12564-020-09663-9.

[13] Aslan, E., and Serin, O. (2020). Transformation in Primary School Sciences Education in the Transition Process from the Empire to the Republic: Science Education in 1924 Primary School Curriculum. Cypriot Journal of Educational Sciences, 15(3), 587-603.

[14] Poveda, D., Morgade, M., Cruz, I., Piñeiro, N., and Gallego, R. (2021). Ethnographic "experimental collaborations" as practitioner methodology. The Qualitative Report, 26(5), 1476-1496. DOI: 10.46743/2160$3715 / 2021.4452$. 